\title{
Growth and Photosynthetic Response of Tomato to Nutrient Solution Concentration at Two Light Levels
}

\author{
D. Schwarz ${ }^{1}$ and H.-P. Kläring \\ Institute for Vegetable and Ornamental Crops, D-14979 Großbeeren, Theodor Echtermeyer Weg 1, Germany \\ M.W. van Iersel and K.T. Ingram² \\ The University of Georgia, College of Agriculture and Environmental Science-Griffin Campus, Department \\ of Horticulture, 1109 Experiment Street, Griffin, GA 30223-1797
}

\begin{abstract}
AdDitional INDEX WORDs. electrical conductivity, EC, gas exchange, hydroponics, $P P F$, photosynthesis, respiration, salinity
Abstract. An increase in nutrient solution concentration to produce high-quality fruit vegetables, such as tomatoes, may reduce growth and yield. One reason might be inhibition of photosynthesis, but results of photosynthesis studies in the literature are inconsistent. In this study, we investigated growth and photosynthesis of whole 'Celebrity' and 'Counter' tomato [Lycopersicon esculentum (L.) Mill.] plants in response to nutrient solution concentration, measured as electrical conductivity (EC). The effects of two levels of photosynthetic photon flux density $\left(P P F=400\right.$ or $\left.625 \mu \mathrm{mol}^{-2} \cdot \mathrm{m}^{-2} \cdot \mathrm{s}^{-1}\right)$ on plant response to nutrient solution EC in a range between 1.25 to $8.75 \mathrm{dS} \cdot \mathrm{m}^{-1}$ in a series of four experiments in gas exchange chambers placed in larger growth chambers were examined. Increasing PPF enhanced tomato growth and photosynthesis but increasing EC diminished them. Reduction of dry weight was $1.9 \%$ to $7.3 \%$, while plant photosynthesis was reduced between $1.7 \%$ and $4.5 \%$ for each $1 \mathrm{dS} \cdot \mathrm{m}^{-1}$. Increasing EC did not decrease dry matter content and leaf photosynthesis. Mean plant dry matter content ranged between 70 and $95 \mathrm{~g} \cdot \mathrm{kg}^{-1}$, and net leaf photosynthesis on the last measurement day was between 7.5 and $11.3 \mu \mathrm{mol} \cdot \mathrm{m}^{-2} \cdot \mathrm{s}^{-1}$, depending on experiment. The decrease in whole plant photosynthesis with an increase in EC was caused by decreased leaf area but not by a decrease in leaf photosynthesis.
\end{abstract}

Commercial greenhouses typically automate the supply of nutrient solution to hydroponically grown plants. Fertilizer-mixing units produce nutrient solution with a constant concentration. The amount of fertilizer solution supplied to plants commonly depends on the time of day or light intensity. Composition and concentration of the nutrient solution are based on published recommendations, which are based on experience, plant species and cultivar, growth stage, and growing system (De Kreij et al., 1997; Göhler, 1960; Hoagland, 1923). Differences are small among the various recommendations for nutrient solution composition for tomato [Lycopersicon esculentum (L.) Mill.] plants of the same age. However, the recommended concentration of the nutrient solution, expressed as electrical conductivity (EC), has increased in recent years, especially in the production of high-quality fruit vegetables, such as tomato (DeKreij et al., 1997; Göhler and Drews, 1989). Moreover, nutrient solution concentration in the root zone may vary in an uncontrolled system if plants take up nutrients and water in different ratios under different environmental conditions.

Increased nutrient solution EC may reduce the growth rate of whole plants and individual plant parts (Al-Harbi, 1995; Caro et al., 1991; Schwarz and Kuchenbuch, 1997; Smith et al., 1992), and enhances ion accumulation (Adams, 1991; Gomez et al., 1992; Knight et al., 1992). Some authors have suggested that increased EC may inhibit photosynthesis, thereby reducing growth, but the results of photosynthesis measurements reported in the literature are inconsistent. Pepino (Solanum muricatum Aiton), eggplant (Solanum melongena $\mathrm{L}$.), and cucumber (Cucumis sativus $\mathrm{L}$.) showed a strong

Received for publication 28 Jan. 2002. Accepted for publication 27 Aug. 2002. We thank The University of Georgia Research Foundation Inc. and the Federal Ministry of Agriculture of Germany for funding this research. The authors express their thanks to Leigh Robicheaux, Larry Freeman, and Keven Calhoun for their valuable help in conducting and analyzing the experiments.

${ }^{1}$ Corresponding author. Mailing address: Institute for Vegetable and Ornamental Crops, Großbeeren/Erfurte.V., Theodor Echtermeyer Weg 1, D-14979 Großbeeren, Germany; e-mail Schwarz@igzev.de.

${ }^{2}$ Department of Crop and Soil Sciences. decrease of leaf photosynthetic rate in response to $\mathrm{NaCl}$ stress when EC increased up to $20 \mathrm{dS} \cdot \mathrm{m}^{-1}$ (Chartzoulakis, 1994; Chen et al., 1999). Awang and Atherton (1994) found only a slight reduction in leaf photosynthesis of strawberry (Fragaria ananassa Duch.).

In contrast, van den Sanden and Veen (1992) found a slight, but significant increase in net photosynthesis of cucumber leaves when increasing the salinity level up to $8 \mathrm{dS} \cdot \mathrm{m}^{-1}$, a range similar to those used by other investigators. Esmailiyeh (1986) and Taleisnik (1987) reported a higher leaf net photosynthesis for tomato in response to elevated nutrient solution EC up to $18 \mathrm{dS} \cdot \mathrm{m}^{-1}$, particularly with $\mathrm{CO}_{2}$ enrichment. Results from different studies are difficult to compare because of interactions with other experimental factors, such as irradiance, $\mathrm{CO}_{2}$ concentration, nutrient solution composition, and cultivar (Esmailiyeh, 1986; Longuenesse and Leonardi, 1994; Taleisnik, 1987; Xu et al., 1995).

Xu et al. (1995) calculated light-response curves for single tomato leaves and determined a maximum leaf photosynthetic rate of $22.5 \mu \mathrm{mol} \cdot \mathrm{m}^{-2} \cdot \mathrm{s}^{-1}$ for a nutrient solution EC of 4.0 and 19.5 $\mu \mathrm{mol} \cdot \mathrm{m}^{-2} \cdot \mathrm{s}^{-1}$ for an EC of $2.5 \mathrm{dS} \cdot \mathrm{m}^{-1}$. These tomato plants were grown in a greenhouse with a nutrient film technique supplying different nutrient solution concentrations of the same nutrient composition. They found similar results for tomato grown in rockwool, although an even greater EC of $5.5 \mathrm{dS} \cdot \mathrm{m}^{-1}$ resulted in a $10 \%$ lower maximum photosynthetic rate compared with an $\mathrm{EC}$ of $4 \mathrm{dS} \cdot \mathrm{m}^{-1}$.

Beside interactions between environmental and cultural factors, the measurement technique (whole plants, single leaves, or leaf discs) can have a large influence on the interpretation of photosynthesis measurements (van Iersel and Bugbee, 2000). For example, a decrease in leaf photosynthesis does not necessarily result in decreased growth or whole plant photosynthesis if the plants produce a larger leaf area.

The goal of the investigations presented here was to test the hypothesis that growth reduction of tomato plants by increases in nutrient solution concentration is caused by a reduction in photosynthesis. Additionally, whether the effect of EC on photosynthesis depends on the light intensity was studied. 


\section{Materials and Methods}

General CONDITIOns. A series of experiments was conducted in two controlled environment chambers [ $(1.80 \times 0.78 \times 1.18 \mathrm{~m}$ $\left(1.66 \mathrm{~m}^{3}\right)$ at the Griffin Campus of The University of Georgia, from October 1997 to March 1998 (Table 1). In all experiments, temperature was maintained at $\approx 25^{\circ} \mathrm{C}$. A first set of two experiments was conducted using the tomato cultivar Celebrity. Nutrient solution EC ranged from 1.25 to $5 \mathrm{dS} \cdot \mathrm{m}^{-1}$ in increments of $1.25 \mathrm{dS} \cdot \mathrm{m}^{-1}$. Using an $\mathrm{EC}>5 \mathrm{dS} \cdot \mathrm{m}^{-1}$ in a subsequent experiment injured 'Celebrity'. Hence, following experiments the more salinity-tolerant cultivar Counter (Schwarz and Kuchenbuch, 1997) was used, and the range of nutrient solution EC was increased to $8.8 \mathrm{dS} \cdot \mathrm{m}^{-1}$.

Twelve-day-old seedlings grown in a climate chamber were planted in 80-mm (0.2-L) pots filled with coarse sand. When they had four leaves, six plants were transplanted into a hydroponic system, consisting of $0.15-\mathrm{m}$-tall plastic trays with a total volume of $12.3 \mathrm{~L}$, filled with $\approx 11.6 \mathrm{~L}$ of nutrient solution. The trays with plants were placed inside acrylic gas exchange chambers $(0.5 \times 0.3 \times$ $0.6 \mathrm{~m}$ ) (van Iersel and Bugbee, 2000), which were then placed inside growth chambers with four gas exchange chambers within each growth chamber. The nutrient solution cycled from a storage tank of $44 \mathrm{~L}, 80 \%$ full, with a flow rate of $2 \mathrm{~L} \cdot \mathrm{min}^{-1}$ (Fig. 1). The composition of the nutrient solution was according to De Kreij et al. (1997). A stock solution was prepared and the desired nutrient solution EC was achieved by diluting the stock solution with demineralized water until the treatment set point was reached. The nutrient solution $\mathrm{EC}$ and the $\mathrm{pH}$ in the storage tank were measured daily and adjusted as needed by diluting or supplying stock solution and $\mathrm{pH}$ was adjusted to 5.6 by adding $\mathrm{H}_{3} \mathrm{PO}_{4}$ or $\mathrm{Ca}(\mathrm{OH})_{2}$.

Two $P P F$ levels ( 400 and $625 \mu \mathrm{mol} \cdot \mathrm{m}^{-2} \cdot \mathrm{s}^{-1}$ ) were maintained in the two growth chambers using fluorescent lights (F72T12/CW/ VH, Sylvania, Mississauga, Ont.), with a 20-h daylength (Table 1). Light levels were measured at the end of each experiment above the top of each plant and averaged for each gas exchange chamber. Although long photoperiods may cause chlorosis and leaf distortion in tomato (Bradley and Janes, 1985), no such effects were observed during our studies, which lasted up to $11 \mathrm{~d}$.
EXPERIMENTAL METHODS. Before the start of gas exchange measurements, the correlation of leaf area with leaf length and width was determined, using leaf area and length/width measurements of 60 leaves (Schwarz and Kläring, 2001). Leaf length $\left(\mathrm{L}_{\mathrm{l}}\right)$ and width $\left(\mathrm{L}_{\mathrm{w}}\right)$ of the plants used for the $\mathrm{CO}_{2}$ exchange measurements were measured before the start of the $\mathrm{CO}_{2}$ exchange measurements to estimate initial leaf area $\left(\mathrm{A}_{\mathrm{lpt} \text { initial }}\right)$.

An open, multichamber system was used to measure $\mathrm{CO}_{2}$ exchange rates $\left(\mathrm{P}_{\text {net }}, \mathrm{R}_{\text {dark }} ;\right.$ Fig. 1). Gas exchange in each chamber was measured for 2 min during a 20-min cycle during the entire study period (van Iersel and Bugbee, 2000). Ambient air was blown into the acrylic chambers and airflow was measured with mass flow meters (GFM37-32, Aalborg Instruments and Controls, Monsey, N.Y.). Environmental conditions within the chamber, such as temperature (copper-constantan thermocouples), and relative humidity (HTO-45R, Rotronic, Huntington, N.Y.) were monitored (Table 1). The difference in $\mathrm{CO}_{2}$ concentration between air entering and exiting a chamber was measured with an infrared gas analyzer (LI-6251, LI-COR, Lincoln, Nebr.). Whole chamber $\mathrm{CO}_{2}$ exchange rate $\left(\mu \mathrm{mol} \cdot \mathrm{s}^{-1}\right)$ was calculated as the product of mass flow $\left(\mathrm{mol} \cdot \mathrm{s}^{-1}\right)$ and the difference in $\mathrm{CO}_{2}$ concentration $\left(\mu \mathrm{mol} \cdot \mathrm{mol}^{-1}\right)$. This resulted in measurements of net photosynthesis $\left(\mathrm{P}_{\text {net }}\right)$ during the light period and dark respiration $\left(\mathrm{R}_{\text {dark }}\right)$ during the dark period. Both $\mathrm{P}_{\text {net }}$ and $\mathrm{R}_{\text {dark }}$ are expressed as positive quantities.

After 8 to $11 \mathrm{~d}$, when the plants had at most 9 leaves, plants were harvested and leaf area $\left(\mathrm{A}_{\text {lpt end }}\right)$ was measured with a leaf area meter (LI-3100, LI-COR) to relate photosynthetic characteristics to leaf area. Shoot and root fresh weight of the plants were determined. Plant parts were dried at $60^{\circ} \mathrm{C}$, and shoots and roots were weighed after $48 \mathrm{~h}$, when the samples had dried to a constant weight. Experiments were carried out while plants were in their exponential growth phase. Hence, an exponential growth curve based on initial and final leaf areas was used to estimate leaf area increase during the experiments (Helgren and Ingestad, 1996):

Area per leaf $\left(\mathrm{A}_{11}, \mathrm{~m}^{2} / \mathrm{leaf}\right)$ :

$\mathrm{A}_{\mathrm{u}}=\mathrm{L}_{\mathrm{w}} \times \mathrm{L}_{1} \times 0.003579$

Table 1. Summary of 4 experiments: duration, cultivars used, environmental conditions such as atmospheric $\mathrm{CO}_{2}$ concentrations, relative humidity ( $\mathrm{RH}$ ), temperature $(\mathrm{T})$, photosynthetic photon flux density $(P P F)$ and the electrical conductivity $(\mathrm{EC})$ levels of the nutrient solution. The experiments were carried out in growth chambers of $1.84 \times 0.78 \times 1.18 \mathrm{~m}^{3}$ at the Georgia Experiment Station, Griffin, Ga., with a 20-h photoperiod.

\begin{tabular}{|c|c|c|c|c|c|c|c|}
\hline Expt. & $\begin{array}{l}\text { Duration } \\
\text { (d) }\end{array}$ & Cultivar & $\begin{array}{c}\mathrm{CO}_{2} \\
\mathrm{concn} \\
\left(\mu \mathrm{mol} \cdot \mathrm{mol}^{-1}\right)\end{array}$ & $\begin{array}{c}\mathrm{RH} \\
\text { day/night } \\
(\%)\end{array}$ & $\begin{array}{c}\mathrm{T} \\
\left({ }^{\circ} \mathrm{C}\right)\end{array}$ & $\begin{array}{c}P P F \\
\left(\mu \mathrm{mol} \cdot \mathrm{m}^{-2} \cdot \mathrm{s}^{-1}\right)\end{array}$ & $\begin{array}{c}\mathrm{EC} \\
\left(\mathrm{dS} \cdot \mathrm{m}^{-1}\right)\end{array}$ \\
\hline \multirow[t]{3}{*}{$\overline{1}$} & 8 & Celebrity & $353 \pm 39$ & $58 / 60 \pm 12$ & $25.3 \pm 0.8$ & 365 & 1.25 \\
\hline & & & & & & & 3.75 \\
\hline & & & & & & & 5.00 \\
\hline \multirow[t]{3}{*}{2} & 10 & Celebrity & $328 \pm 55$ & $64 / 64 \pm 10$ & $24.5 \pm 0.7$ & 365 & 1.25 \\
\hline & & & & & & & 3.75 \\
\hline & & & & & & & 5.00 \\
\hline \multirow[t]{4}{*}{3} & 11 & Counter & $656 \pm 66$ & $53 / 58 \pm 10$ & $25.0 \pm 0.9$ & 400 & 1.25 \\
\hline & & & & & & 625 & 3.75 \\
\hline & & & & & & & 6.25 \\
\hline & & & & & & & 8.75 \\
\hline
\end{tabular}


Initial leaf area per plant $\left(\mathrm{A}_{\mathrm{lp} \mathrm{tinitial}}, \mathrm{m}^{2} /\right.$ plant $)$ :

$\mathrm{A}_{\text {lp t initial }}=\sum_{\mathrm{i}=1}^{\mathrm{b}} \mathrm{A}_{11}$

where $b$ is the number of leaves per plant.

Leaf area per plant during the experiment $\left(\mathrm{A}_{\mathrm{lp} t}, \mathrm{~m}^{2} / \mathrm{plant}\right)$ :

$\mathrm{A}_{\mathrm{lpt}}=\mathrm{A}_{\mathrm{lp} \mathrm{t} \text { initial }}$ e $\left[\ln \mathrm{A}_{\mathrm{lp} \mathrm{tend}}-\ln \mathrm{A}_{\mathrm{lpt \text {initial }}} /\left(\mathrm{t}_{\text {end }}-\mathrm{t}_{\text {initial }}\right)\right.$

$\left.\times\left(\mathrm{t}-\mathrm{t}_{\text {initial }}\right)\right]$

where $t(d)$ is time after placing the plants in the trays.

The following photosynthetic characteristics were calculated either per six-plant tray or per unit leaf area:

Daily average gross photosynthesis during the light period $\left(\mathrm{P}_{\text {gross }}\right.$, $\left.\mu \mathrm{mol} \cdot \mathrm{s}^{-1}\right)$ :

$\mathrm{P}_{\text {gross }}=\mathrm{P}_{\text {net avg }}+\mathrm{R}_{\text {dark avg }}$

where $P_{\text {net avg }}$ and $\mathrm{R}_{\text {dark avg }}$ are the average $\mathrm{CO}_{2}$ exchange rates measured during the light and dark period, respectively. This calculation assumes that respiration is similar in the light and dark.

Cumulative carbon fixed in photosynthesis [CCF, (mol)]:

$\mathrm{CCF}=\sum_{\mathrm{i}=1}^{\mathrm{n}_{1}}\left(\mathrm{P}_{\text {gross }} \times 72000\right)$

where $n$ is the number of days included in the measurements and 72000 the factor needed to calculate CCF per day, the number of seconds during the light period.

Cumulative carbon gain (CCG, mol), the total net amount of carbon taken up by the plants:
$\mathrm{CCG}=\sum_{\mathrm{i}=1}^{\mathrm{n}}\left[\left(\mathrm{P}_{\text {net avg }}+\mathrm{P}_{\text {light }}\right)-\left(\mathrm{R}_{\text {dark avg }} \times \mathrm{T}_{\text {dark }}\right)\right]_{\mathrm{i}}$

where $\mathrm{t}_{\text {light }}$ and $\mathrm{t}_{\text {dark }}$ are the duration of the light $(20 \mathrm{~h})$ and dark periods (4 h), respectively.

Carbon use efficiency (CUE, dimensionless), ratio between carbon incorporated into plant dry mass and the total amount of carbon fixed in photosynthesis:

$\mathrm{CUE}=\mathrm{CCG} / \mathrm{CCF}$

To compare $\mathrm{P}_{\text {gross }}, \mathrm{P}_{\text {net }}$, and $\mathrm{R}_{\text {dark }}$ of the different treatments, data were corrected for differences in plant size. This allowed for comparisons on the basis of equal leaf areas of $\mathrm{A}_{\mathrm{lpt}}=0.05 \mathrm{~m}^{2} /$ plant. To do this, the relationship between these characteristics (P) and leaf area was modeled with second order polynomials:

$\mathrm{P}=\mathrm{d}_{\mathrm{o}}+\mathrm{d}_{1} \mathrm{~A}_{\mathrm{lpt}}+\mathrm{d}_{2} \mathrm{~A}_{\mathrm{lpt}}^{2}$

where $d_{o}, d_{1}$, and $d_{2}$ are the regression coefficients for the relevant characteristic and the value of $\mathrm{P}$ at a leaf area of $0.05 \mathrm{~m}^{2} /$ plant was estimated. Parameters of Eq. [8] were estimated by quasi linear regression analysis (Quasi Newton estimation procedure, STATISTICA for Windows, StatSoft, Tulsa, Okla.).

Conditions not under investigation such as cultivar and plant properties at the start of the experiment varied among experiments. They were estimated as the levels of a factor $\alpha$, the experimentspecific block effect, and tested for significance by $\mathrm{F}$ tests. The investigated variables PPF and EC were introduced as concomitant variables. Their effects were estimated by regression and tested for significance by $t$ tests. Thus, we considered the linear model for the analysis of covariance for the observations $\mathrm{P}_{\mathrm{ij}}$ :

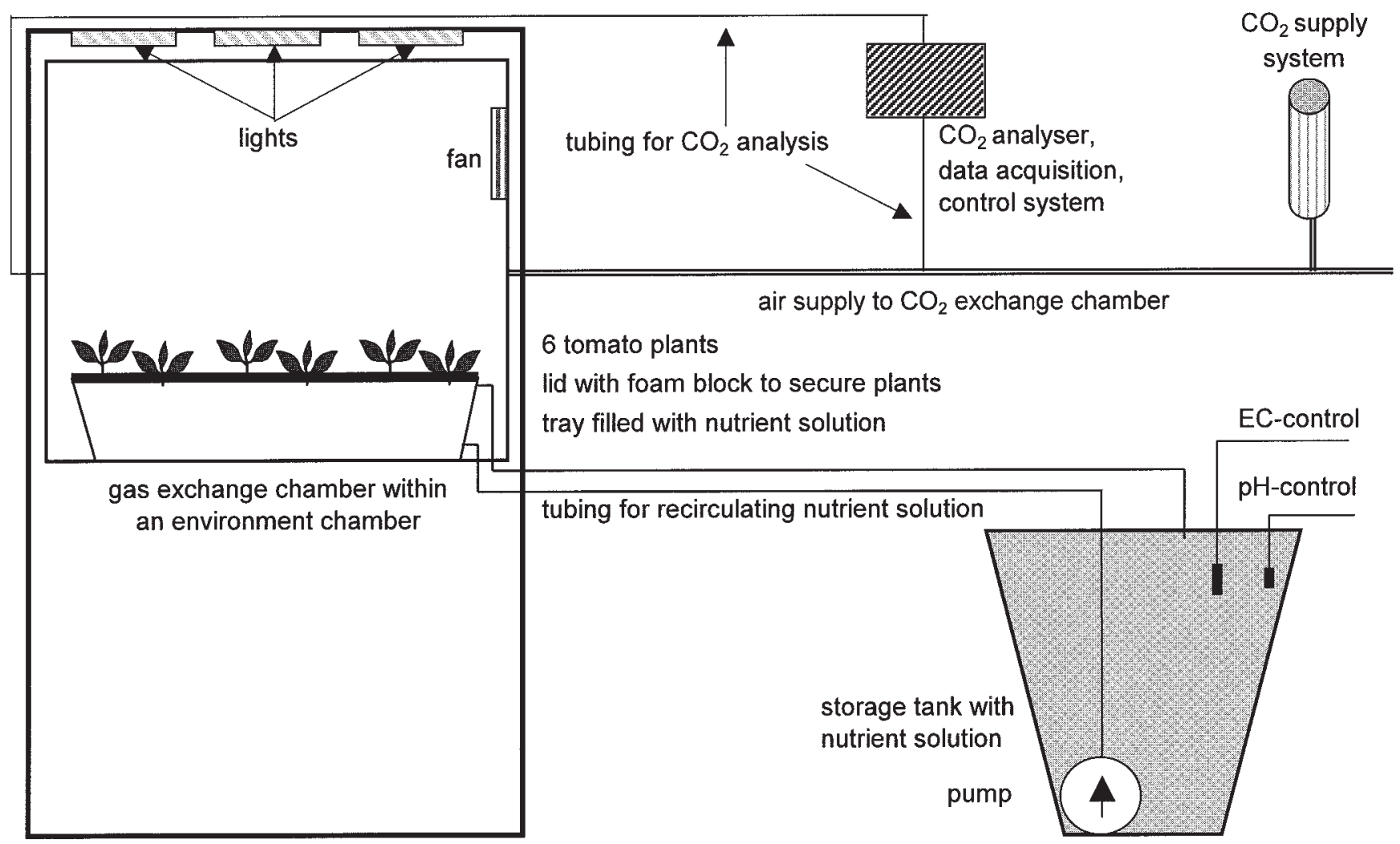

Fig. 1. Schematic view of the setup used for supply and control of nutrient solution electrical conductivity and photosynthesis measurements. Eight acrylic gas exchange chambers were placed inside two larger plant growth chambers. Tomato plants were grown inside these gas exchange chambers using a recirculating, hydroponic irrigation system. 

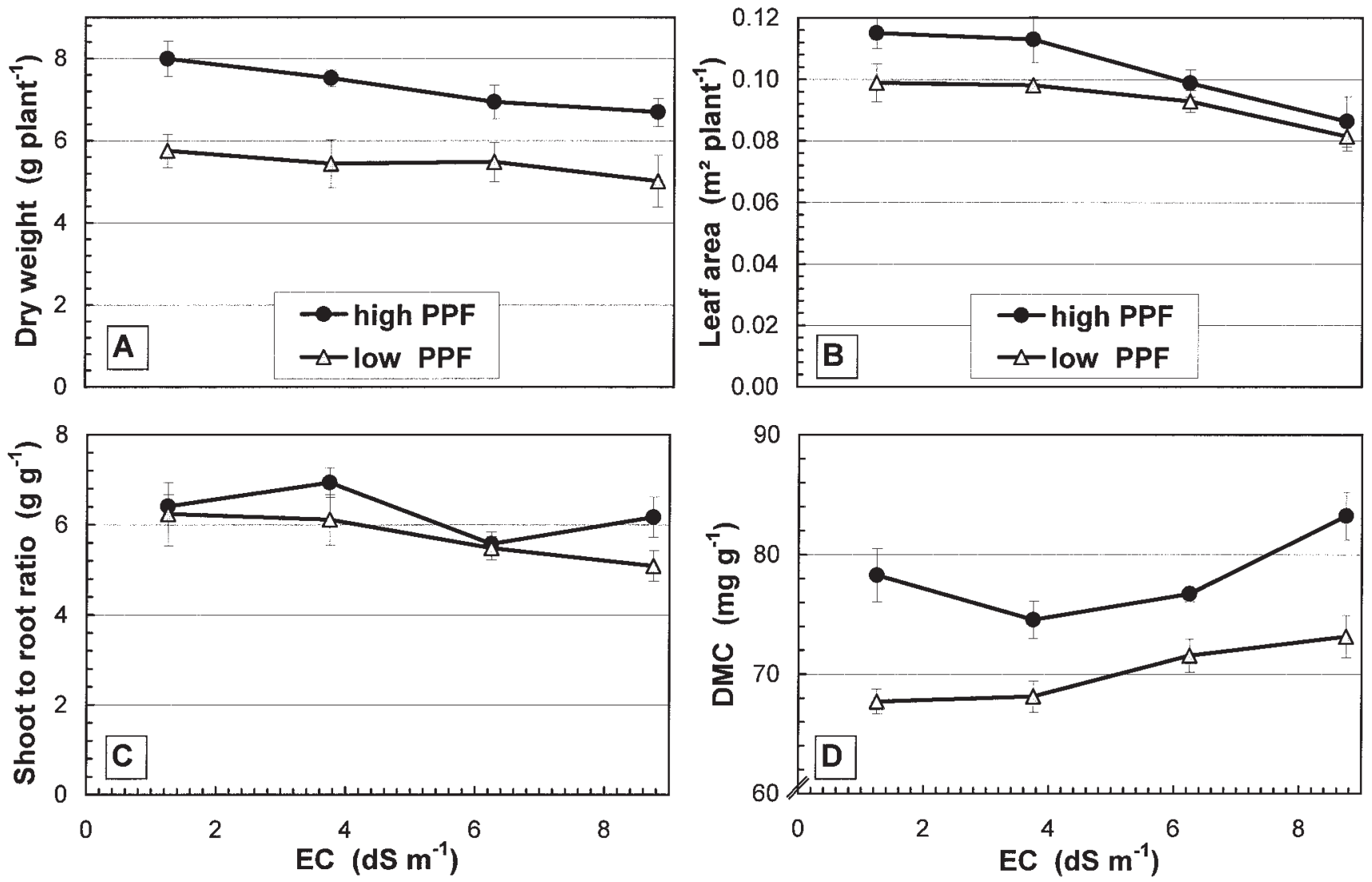

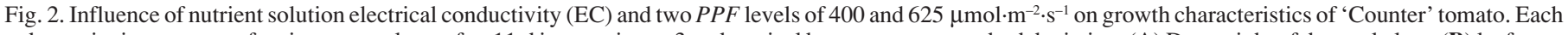
data point is an average for six tomato plants after $11 \mathrm{~d}$ in experiment 3 and vertical bars represent standard deviation. (A) Dry weight of the total plant, (B) leaf area,

(C) shoot to root ratio (based on dry weight), (D) dry matter content (DMC) of the total plant.

$P_{i j}=\mu+\alpha_{i}+\beta\left(P_{P P F}-\overline{P P F}\right)+\gamma\left(E C_{i j}-\overline{E C}\right)+\varepsilon_{i j}, i=1, \ldots, n, j=1, \ldots, m$ $\overline{\mathrm{PPF}}=1 / \mathrm{nm} \sum_{\mathrm{i}, \mathrm{j}} \mathrm{PPF}_{\mathrm{ij}}$

$\overline{\mathrm{EC}}=1 / \mathrm{nm} \sum_{\mathrm{i}, \mathrm{j}} \mathrm{EC}_{\mathrm{ij}}$

where $\mathrm{P}_{\mathrm{ij}}$ denotes the dependent variable of growth or photosynthesis measured, $\mathrm{PPF}_{\mathrm{ij}}$ and $\mathrm{EC}_{\mathrm{ij}}$ denote the concomitant variables measured, $\mathrm{n}$ and $\mathrm{m}$ stand for the number of the experiments and the number of the gas exchange chambers, respectively, while $\varepsilon_{\mathrm{ij}}$ is a random error term. The model contains the constants $\mu, \alpha_{i}, \beta$, and $\gamma$. The constant $m$ may be interpreted as overall mean of all experiments, $\mathrm{a}_{\mathrm{i}}$ as the block effect of the particular experiment, while $b$ and $\mathrm{g}$ are regression coefficients, describing the effects of $P P F$ and EC, respectively.

Model constants $\mu, \alpha_{i}, \beta$, and $\gamma$ were estimated by analysis of covariance using the STATISTICA for Windows (StatSoft). Significance of the regression was tested at level $P=0.05$. Effect of $\mathrm{CO}_{2}$ concentration could not be separated from the cultivar effect, since both experiments with low $\mathrm{CO}_{2}$ concentration were conducted with 'Celebrity', while both experiments at elevated $\mathrm{CO}_{2}$ were done with 'Counter'.

\section{Results}

GroWTH ANALYSIS. Eight to $11 \mathrm{~d}$ after planting, more plant fresh weight, dry weight, and leaf area were produced by the treatments with higher $P P F$. Treatment influence is depicted in Fig. 2 for experiment 3 as representative of all experiments. In general, ANOVA showed a significant influence of $P P F$ on all measured growth characteristics (Table 2). The relative increase in dry weight at high $P P F$ was bigger than that in fresh weight due to higher dry matter content at higher $P P F$ (Fig. 2D).

Table 2. Effects of photosynthetic photon flux density $(P P F)$ and nutrient solution electrical conductivity (EC) on growth characteristics at the end of climate chamber experiments. $P_{i j}=\mu+\alpha_{i}+\beta\left(P P F_{i j}-P P F\right)+\gamma\left(E_{i j}-E C\right)+\varepsilon_{i j}, i=1, \ldots, 4, j=1, \ldots, 8$. Model constants $\mu, \alpha_{i}, \beta$, and $\gamma$ were estimated using analysis of covariance; $\mu$ is the overall mean, $\alpha_{\mathrm{i}}$ is the experiment-specific block effect, $\beta$ and $\gamma$ are the regression coefficients describing $P P F$ and EC influence, respectively, $\varepsilon_{\mathrm{ij}}$ is a random error term. Regression parameters were statistically significant unless followed by NS $(P=0.05)$. Units in the table are those for $\mu$.

\begin{tabular}{|c|c|c|c|c|c|c|c|c|c|c|c|c|}
\hline \multirow{2}{*}{$\begin{array}{l}\text { Model } \\
\text { constant }\end{array}$} & \multicolumn{3}{|c|}{$\begin{array}{c}\text { Fresh } \\
\text { wt } \\
\text { (g/plant) }\end{array}$} & \multicolumn{3}{|c|}{$\begin{array}{c}\text { Dry } \\
\text { wt } \\
\text { (g/plant) }\end{array}$} & \multicolumn{3}{|c|}{$\begin{array}{l}\text { Dry matter } \\
\text { content } \\
\left(\mathrm{mg} \cdot \mathrm{g}^{-1}\right)\end{array}$} & \multicolumn{2}{|c|}{$\begin{array}{l}\text { Shoot-root } \\
\text { ratio } \\
\left(\mathrm{g} \cdot \mathrm{g}^{-1}\right)\end{array}$} & \multirow{2}{*}{$\begin{array}{c}\begin{array}{c}\text { Leaf } \\
\text { area }\end{array} \\
\left(\mathrm{m}^{2} / \text { plant }\right)\end{array}$} \\
\hline & Root & Shoot & Total & Root & Shoot & Total & Root & Shoot & Total & Fresh & Dry & \\
\hline $\bar{\mu}$ & 15.41 & 57.74 & 73.15 & 0.83 & 4.92 & 5.75 & 55.54 & 86.91 & 80.25 & 4.12 & 6.63 & 0.0796 \\
\hline$\beta$ & 0.0171 & 0.0339 & 0.0510 & 0.0012 & 0.0043 & 0.0055 & 0.0219 & 0.0407 & 0.0338 & -0.0040 & -0.0050 & 0.000025 \\
\hline$\gamma$ & -0.576 & -2.867 & -3.446 & -0.0314 & -0.142 & -0.173 & $0.065^{\mathrm{NS}}$ & 2.226 & 1.788 & -0.176 & $-0.108^{\mathrm{NS}}$ & -0.00373 \\
\hline
\end{tabular}


Table 3. Effects of photosynthetic photon flux density $(P P F)$ and nutrient solution electrical conductivity $(\mathrm{EC})$ on gross photosynthesis $\left(\mathrm{P}_{\text {gross }}\right)$, net photosynthesis $\left(\mathrm{P}_{\text {net }}\right)$, dark respiration $\left(\mathrm{R}_{\text {dark }}\right)$, cumulative carbon gain $(\mathrm{CCG})$, and carbon use efficiency $(\mathrm{CUE})$. $\mathrm{P}$ and $\mathrm{R}$ were calculated from the last measurement day, CCG and CUE were calculated as cumulative amounts over the growth period. Results are expressed per tray with six plants, per final $\left(A_{l p t \text { end }}\right)$, or per equal leaf area $\left(A_{1 p t}\right.$, Eq. [3] $) . P_{i j}=\mu+\alpha_{i}+\beta\left(P_{P} F_{i j}-P P F\right)+\gamma\left(E C_{i j}-E C\right)+\varepsilon_{i j}, i=1, \ldots, 4, j=1, \ldots, 8 . M o d e l$ constants $\mu, \alpha_{i}, \beta$, and $\gamma$ were estimated using analysis of covariance; $\mu$ is the overall mean, $\alpha_{i}$ is the experiment-specific block effect, $\beta$ and $\gamma$ are the regression coefficients describing $P P F$ and $\mathrm{EC}$ influence, respectively, $\varepsilon_{\mathrm{ij}}$ is a random error term. Regression parameters were statistically significant unless followed by NS $(P=0.05)$.

\begin{tabular}{|c|c|c|c|c|c|c|c|c|c|c|c|}
\hline \multirow[b]{3}{*}{$\begin{array}{l}\text { Model } \\
\text { constant }\end{array}$} & \multicolumn{3}{|c|}{$\mathrm{P}_{\text {gross }}$} & \multicolumn{3}{|c|}{$\mathrm{P}_{\text {net }}$} & \multicolumn{3}{|c|}{$\mathrm{R}_{\text {dark }}$} & \multirow[b]{2}{*}{ CCG } & \multirow[b]{2}{*}{ CUE } \\
\hline & \multicolumn{2}{|c|}{ Daily mean } & \multirow{2}{*}{$\begin{array}{c}\mathrm{A}_{\mathrm{lpt}}= \\
0.05 \mathrm{~m}^{2} \\
\mu \mathrm{mol} \cdot \mathrm{m}^{-2} \cdot \mathrm{s}^{-1}\end{array}$} & \multicolumn{2}{|c|}{ Daily mean } & \multirow{2}{*}{$\begin{array}{c}\mathrm{A}_{\mathrm{lpt}}= \\
0.05 \mathrm{~m}^{2} \\
\mu \mathrm{mol} \cdot \mathrm{m}^{-2} \cdot \mathrm{s}^{-1}\end{array}$} & \multicolumn{2}{|c|}{ Daily mean } & \multirow{2}{*}{$\begin{array}{c}\mathrm{A}_{\mathrm{lpt}}= \\
0.05 \mathrm{~m}^{2} \\
\mu \mathrm{mol} \cdot \mathrm{m}^{-2} \cdot \mathrm{s}^{-1}\end{array}$} & & \\
\hline & $\begin{array}{l}\text { per tray } \\
\mu \mathrm{mol} \cdot \mathrm{s}^{-1}\end{array}$ & $\begin{array}{c}\text { per } A_{1 p t \text { end }} \\
\mu \mathrm{mol} \cdot \mathrm{m}^{-2} \cdot \mathrm{s}^{-1}\end{array}$ & & $\begin{array}{l}\text { per tray } \\
\mu \mathrm{mol} \cdot \mathrm{s}^{-1}\end{array}$ & $\begin{array}{c}\text { per } \mathrm{A}_{\mathrm{lpt} \text { end }} \\
\mu \mathrm{mol} \cdot \mathrm{m}^{-2} \cdot \mathrm{s}^{-1}\end{array}$ & & $\begin{array}{l}\text { per tray } \\
\mu \mathrm{mol} \cdot \mathrm{s}^{-1}\end{array}$ & $\begin{array}{c}\text { per } \mathrm{A}_{\mathrm{lptend}} \\
\mu \mathrm{mol} \cdot \mathrm{m}^{-2} \cdot \mathrm{s}^{-1}\end{array}$ & & $\begin{array}{r}\text { per t } \\
\text { mo }\end{array}$ & \\
\hline$\overline{\mathrm{m}}$ & 4.19 & 11.52 & 12.57 & 3.37 & 9.24 & 11.05 & 0.82 & 2.28 & 2.56 & 1.28 & 0.736 \\
\hline $\mathrm{b}$ & 0.00298 & 0.0109 & 0.0141 & 0.00240 & 0.00859 & 0.0103 & 0.000581 & 0.00230 & 0.00303 & 0.00156 & $0.00003^{\mathrm{Ns}}$ \\
\hline $\mathrm{g}$ & -0.0599 & 0.311 & $-0.0811^{\mathrm{NS}}$ & -0.0542 & 0.224 & $-0.0346^{\mathrm{NS}}$ & $-0.00573^{\mathrm{NS}}$ & 0.0865 & $0.0108^{\mathrm{NS}}$ & -0.0343 & -0.00216 \\
\hline
\end{tabular}

Increasing nutrient solution EC significantly decreased total fresh weight, dry weight, and leaf area, but increased dry matter content (Table 2, Fig. 2). In experiment 4, a slight enhancement in fresh and dry weight was measured for 'Counter' with an increase in EC from 1.25 to $3.75 \mathrm{dS} \cdot \mathrm{m}^{-1}$. In contrast to PPF effects, EC treatments generally influenced fresh weight more than dry weight, as total dry matter content was positively correlated with nutrient solution EC (Fig. 2D; Table 2). Root dry matter content increased with EC only in experiment 2. Shoot to root ratio on a fresh weight basis decreased significantly with increasing EC (Fig. 2C), while shoot to root ratio on a dry weight basis was not affected by EC (Table 2). Apparently, increased EC reduced shoot and root dry weight to the same extent, so that shoot to root ratio response was not significant. No interactive effects between $P P F$ and EC on growth characteristics were found.

Gross AND NET PHOTOSYNTHESIS. Increasing $P P F$ significantly increased $\mathrm{P}_{\text {net }}, \mathrm{P}_{\text {gross }}$, and the total amount of carbon fixed by plants during the entire growing period (Table 3 ). The effects of photosynthesis were similar for both whole plants and on a leaf area basis, and in all experiments. Treatment influence is depicted in Figs. 3 and 4 for Expt. 3 as representative of all experiments. No significant influence of $P P F$ was found on CUE.

Nutrient solution EC significantly affected photosynthetic characteristics (Table 3). Increasing nutrient solution EC decreased whole plant $\mathrm{P}_{\text {gross }}, \mathrm{P}_{\text {net }}$ (Fig. 3A), and CCG. Influences were similar on all these characteristics. Gross photosynthesis and $\mathrm{P}_{\text {net }}$ increased significantly with increasing $\mathrm{EC}$ when they were expressed on a leaf area basis (Table 3, Fig. 3B).

Because EC also affected leaf area (Fig. 2B), it was not clear whether EC directly affected photosynthesis or if this was an indirect effect caused by differences in leaf area. Therefore, we also compared photosynthetic characteristics on basis of equal leaf area. Leaf area development of the plants was estimated using Eq. [3] and $\mathrm{P}_{\text {gross }}$ and $\mathrm{P}_{\text {net }}$ were estimated according to Eq. [8] using $\mathrm{A}_{\mathrm{lpt}}=0.05$ $\mathrm{m}^{2}$, because leaf area at the end of all experiments was above 0.05 $\mathrm{m}^{2} /$ plant. Models (Eq. [9]) were calculated for $P P F$ and EC treatments in all experiments (Table 3 ) and depicted for $\mathrm{P}_{\text {net }}$ only from Expt. 3 for better illustration (Fig. 3B). From this analysis based on equal leaf area, nutrient solution EC significantly influenced CUE, which decreased with increasing nutrient solution EC (Table 3). No significant interactive effects of $P P F$ and EC were found on photosynthetic characteristics.

DARK RESPIRATION. Both whole plant respiration and respiration per unit leaf area were positively correlated with $P P F$ (Table 3, Fig. 4A and B).

Increase of nutrient solution EC did not significantly affect whole plant respiration, but increased respiration per unit leaf area (Table 3, Fig. 4A and B). The effect of increasing nutrient solution EC was not significant when respiration was estimated for plants with equal leaf area of $0.05 \mathrm{~m}^{2}$.

\section{Discussion}

Maas and Hoffman (1977) stated that, for many crops, biomass production declines linearly with increasing nutrient solution concentration after passing a threshold value. According to Adams (1991) and Sonneveld (1988), a growth reduction is expected for
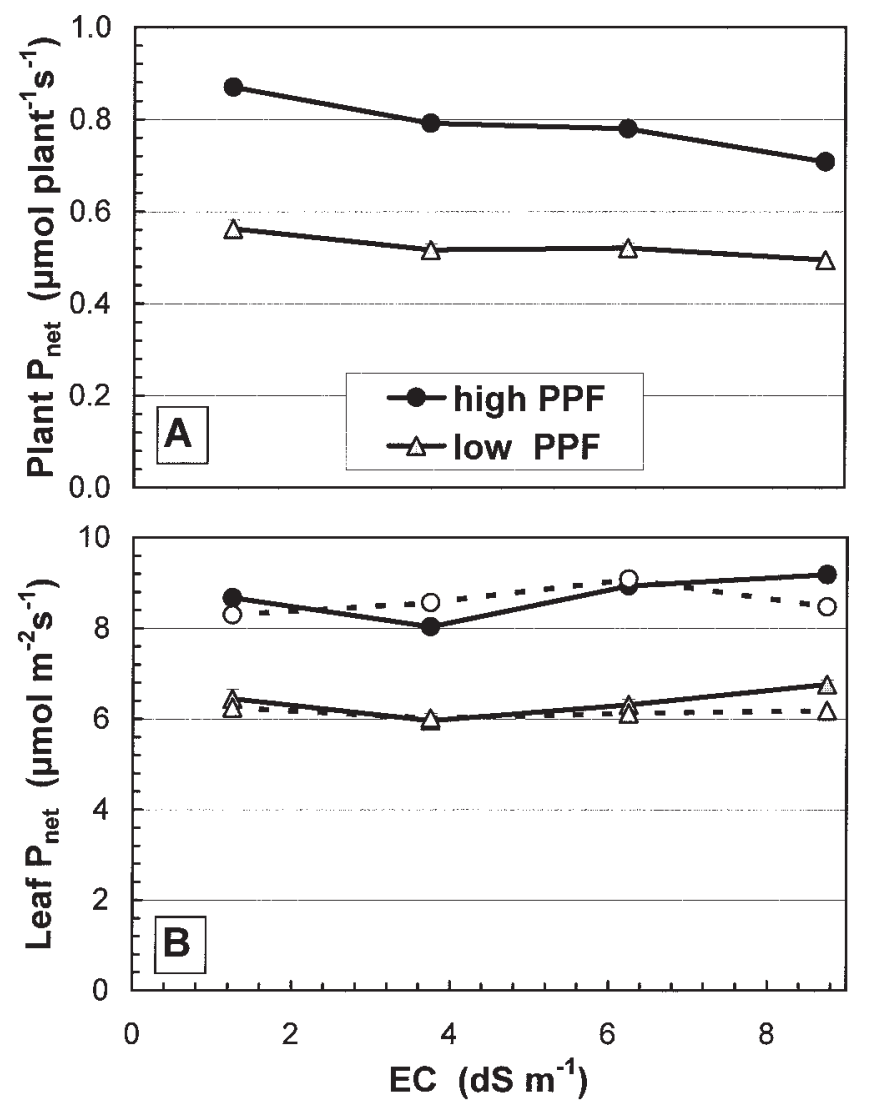

Fig. 3. 'Counter' tomato plant net photosynthetic rate $\left(\mathrm{P}_{\text {net }}\right)$ after 11 din experiment 3. Data were calculated as average $\mathrm{CO}_{2}$ exchange rates during the light period $(20 \mathrm{~h})$ from 60 measurements of six plants for two PPF levels at 400 and $625 \mu \mathrm{mol} \cdot \mathrm{m}^{-2} \cdot \mathrm{s}^{-1}$ and four EC levels. Vertical bars represent standard deviation of the repeated measurements. Error bars not shown are within the limit of the symbol. (A) Plant $\mathrm{P}_{\text {net }}$, (B) leaf $\mathrm{P}_{\text {net }}$, the dotted lines depict estimated leaf $\mathrm{P}_{\text {net }}$ for plants with an equal leaf area $\left(\mathrm{A}_{\mathrm{lp}}\right.$, Eq. [3]) of $0.05 \mathrm{~m}^{2}$. 
tomato in a range of $6 \%$ to $10 \%$ for each $1 \mathrm{dS} \cdot \mathrm{m}^{-1}$ increase in nutrient solution EC, depending on cultivar and nutrient composition. Our results confirm these findings, although the growth reduction in Expts. 3 and 4 was $<4 \%$. Reasons for the smaller growth reduction and the higher shoot to root ratio in Expts. 3 and 4 could be the use of a different cultivar or an increase in $\mathrm{CO}_{2}$ concentration. Dalton
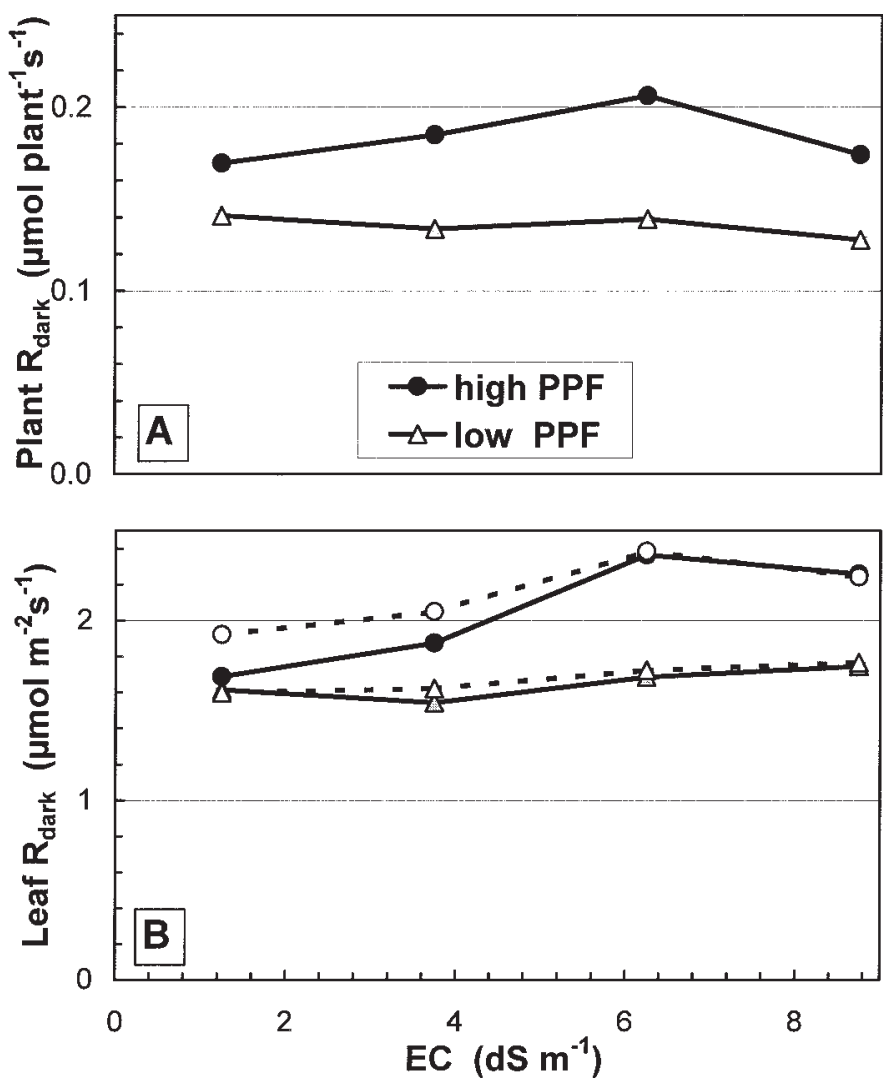

Fig. 4. 'Counter' tomato plant dark respiration rate $\left(\mathrm{R}_{\text {dark }}\right)$ after $11 \mathrm{~d}$ in experiment 3. Data were calculated as average $\mathrm{CO}_{2}$ exchange rates during the dark period (4 h) from 12 measurements of six plants for two PPF levels at 400 and $625 \mu \mathrm{mol} \cdot \mathrm{m}^{-2} \cdot \mathrm{s}^{-1}$ and at four EC levels. Vertical bars represent standard deviation of the repeated measurements. Error bars not shown are within the limit of the symbol. (A) Plant $\mathrm{R}_{\text {dark }}$, (B) leaf $\mathrm{R}_{\text {dark }}$, the dotted lines depict estimated leaf $\mathrm{R}_{\text {dark }}$ for plants with a equal leaf area $\left(\mathrm{A}_{\mathrm{lpt}}, \mathrm{Eq}\right.$. [3] $)$ of $0.05 \mathrm{~m}^{2}$.

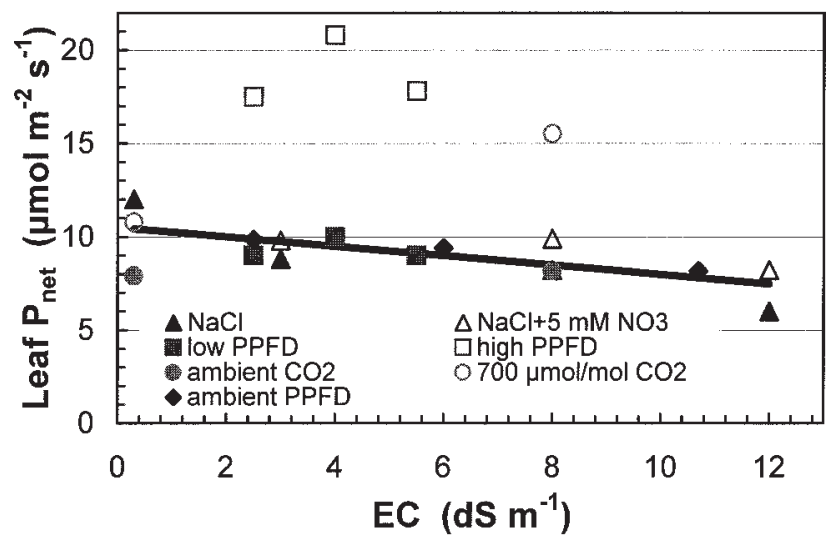

Fig. 5. Recalculated results of 21 net photosynthesis $\left(\mathrm{P}_{\text {net }}\right)$ measurements with tomato grown under different nutrient solution $\mathrm{EC}$ treatments. The regression line represents the best fit through the data excluding those data collected at high light intensity or high atmospheric $\mathrm{CO}_{2}$ concentration $\left(\mathrm{P}_{\text {net }}=10.5-0.25 \times \mathrm{EC}\right.$, $r=0.82$ ). Symbols present different treatments in experiments of Heuer and Feigin (1993) $\boldsymbol{\Delta}$ and $\Delta$; Xu et al. (1995) $\square$ and $\square$; Esmailiyeh (1986) $\bigcirc$ and $\bigcirc$; and Gao et al. (1994) $\%$. and Poss (1990) and Dalton et al. (1997) showed that EC effects depend on temperature. They found that an increase in temperature from 18 to $25^{\circ} \mathrm{C}$ shifted the EC threshold for decrease of growth from 1.8 to $3.0 \mathrm{dS} \cdot \mathrm{m}^{-1}$. This might explain why in our experiments, with a mean temperature of $25^{\circ} \mathrm{C}$, reductions in dry weight and leaf area were observed for EC values higher than $3.75 \mathrm{dS} \cdot \mathrm{m}^{-1}$.

Light intensity also may have an effect on the EC threshold for growth reduction. Esmailiyeh (1986) and Xu et al. (1995) found no EC effect under low light conditions $\left(<200 \mu \mathrm{mol} \cdot \mathrm{m}^{-2} \cdot \mathrm{s}^{-1}\right)$ when EC was below $8 \mathrm{dS} \cdot \mathrm{m}^{-1}$, but they did find an effect of EC on growth at a higher light intensity $\left(1000 \mu \mathrm{mol} \cdot \mathrm{m}^{-2} \cdot \mathrm{s}^{-1}\right)$.

Our finding that whole plant photosynthesis decreases with increasing nutrient solution EC (Table 3; Fig. 3A) is consistent with other results for tomato and other crops (Chartzoulakis, 1994; Chen et al., 1999; Esmailiyeh, 1986), but the effect of salinity $(\mathrm{NaCl})$ or EC on photosynthesis per unit leaf area is less clear. EC effects on leaf photosynthesis of tomato already published are summarized in Fig. 5 (Esmailiyeh, 1986; Gao et al., 1994; Heuer and Feigin, 1993; Xu et al., 1995). Except for experiments conducted under high $P P F$ levels $\left(1000 \mu \mathrm{mol} \cdot \mathrm{m}^{-2} \cdot \mathrm{s}^{-1}\right.$; $\mathrm{Xu}$ et al., 1995) and elevated $\mathrm{CO}_{2}$ concentration $\left(700 \mu \mathrm{mol} \cdot \mathrm{mol}^{-1}\right.$; Esmailyieh, 1986), a linear regression fits the data $(r=0.82$, Fig. 5). The differences in response among the experiments may be due to differences in plant developmental stage. Chartzoulakis (1994) has shown that plants become less sensitive to salt stress later in development. Based on these results, the decrease in $\mathrm{P}_{\text {net }}$ was $0.25 \mu \mathrm{mol} \cdot \mathrm{m}^{-2} \cdot \mathrm{s}^{-1}$ for each $1 \mathrm{dS} \cdot \mathrm{m}^{-1}$ increase in $\mathrm{EC}$, or $\approx 2.6 \%$ of the maximum $\mathrm{P}_{\text {net }}\left(10.8 \mu \mathrm{mol} \cdot \mathrm{m}^{-2} \mathrm{~s}^{-1}\right)$.

With the exception of Esmailiyeh (1986), studies of EC effects on leaf photosynthesis mentioned above were performed with single-leaf gas exchange systems. Although single-leaf photosynthesis measurements yield important physiological information, they are poor indicators of plant growth, because they do not take into account the total leaf area of plants. In addition, the measured leaf may not be representative of all the leaves in the canopy (van Iersel and Bugbee, 2000). Whole-plant photosynthesis measurements bypass these limitations of leaf photosynthesis measurements and give a direct indication of the plant growth rate. The good agreement between the reduction of total dry weight by $3 \%$ and the reduction in CCG by $2.7 \%$ indicates that our gas exchange measurements were an accurate indicator of plant growth (Tables 2 and 3).

Esmailiyeh (1986) measured photosynthesis of whole plants in a cuvette and found an increased leaf photosynthesis rate with increasing EC. We found a similar increase in leaf photosynthesis (Fig. 3B, Table 3). However, these measurements do not take into account that the leaf area per plant differed among treatments. Larger plants have more intraplant competition for light, reducing the amount of light intercepted per unit leaf area, which would be expected to lower photosynthetic rates per unit leaf area. At a common leaf area per plant, EC did not significantly affect photosynthetic rates (Table 3 ). Our results also indicate that leaf area decrease is a response to increasing EC (Fig. 2B). This resulted in a decrease in whole-plant photosynthesis with increasing EC (Fig. $3 \mathrm{~A})$. The decrease in leaf area explains the apparently contradictory finding that leaf photosynthesis remained constant or increased, while whole-plant photosynthesis decreased with increasing EC.

Another reason for the decrease in leaf photosynthesis with increasing nutrient solution EC mentioned by some authors (Heuer and Feigin, 1993; Xu et al., 1995) is that the response may depend on the length of the treatment period. Chartzoulakis (1994) showed that the decrease in photosynthesis becomes more severe as cucumber plants are exposed to salt stress for longer periods. While plants in our experiments were exposed to salt stress for $\approx 10 \mathrm{~d}$, those of $\mathrm{Xu}$ 
et al. (1995) and Heuer and Feigin (1993) were exposed for 21 and $38 \mathrm{~d}$, respectively, and exhibited a stronger response to salt stress.

Heuer and Feigin (1993) stated that the influence of nutrient solution EC on photosynthesis depends both on total nutrient solution concentration and ionic composition. They showed that adding $5 \mathrm{~mm} \mathrm{Ca}\left(\mathrm{NO}_{3}\right)_{2}$ to a nutrient solution enriched with $\mathrm{NaCl}$ in a range between 35 to $120 \mathrm{~mm}$ increased leaf photosynthesis. In most published experiments, $\mathrm{NaCl}$ was added to increase EC (Chartzoulakis, 1994; Dalton et al., 1997; Esmailiyeh, 1986; Gao et al., 1994). However, to improve tomato fruit quality, greenhouse growers often use more stock solution, thereby adding more macronutrients. This may affect plants differently from adding $\mathrm{NaCl}$. Research on effects of nutrient solution composition on photosynthesis is only available for increasing sulfate and nitrate amounts (Heuer and Feigin, 1993; Xu et al., 1996).

Our experiments and previous reports show that an increase in EC decrease whole plant photosynthesis of tomato. This reduction in total plant growth apparently was caused by decreased leaf area and not by changes in leaf photosynthesis per se, since an increase in nutrient solution EC up to $8.75 \mathrm{dS} \cdot \mathrm{m}^{-1}$ did not significantly affect leaf photosynthesis in the experiments (Table 3, Fig. 3).

\section{Literature Cited}

Adams, P. 1991. Effects of increasing the salinity of the nutrient solution with major nutrients or sodium chloride on the yield, quality and composition of tomatoes grown in rockwool. J. Hort. Sci. 66:201-207.

Al Harbi, A.R. 1995. Growth and nutrient composition of tomato and cucumber seedlings as affected by $\mathrm{NaCl}$ salinity and supplemental Can. J. Plant Nutr. 18:1403-1416.

Awang, Y.B. and J.G. Atherton. 1994. Salinity and shading effects on leaf water relations and ionic composition of strawberry plants grown on rockwool. J. Hort. Sci. 69:377-383.

Bradley, F.M. and H.W. Janes. 1985. Carbon partitioning in tomato leaves exposed to continuous light. Acta Hort. 174:293-302.

Caro, M., V. Cruz, J. Cuartero, M.T. Estan, and M.C. Bolarin. 1991. Salinity tolerance of normal-fruited and cherry tomato cultivars. Plant Soil 136:249-255.

Chartzoulakis, K. 1994. Photosynthesis, water relations and leaf growth of cucumber exposed to salt stress. Scientia Hort. 59:27-35.

Chen, K., G. Hu, N. Keutgen, M.J.J. Janssens, and F. Lenz. 1999. Effects of $\mathrm{NaCl}$ salinity and $\mathrm{CO}_{2}$ enrichment on pepino (Solanum muricatum Ait.). II. Leaf photosynthetic properties and gas exchange. Scientia Hort. 81:43-56.

Dalton, F.N. and J.A. Poss. 1990. Water transport and salt loading: A unified concept of plant response to salinity. Acta Hort. 278:187-194.

Dalton, F.N., A. Maggio, and G. Piccinni. 1997. Effect of root temperature on plant response functions for tomato-comparison of static and dynamic salinity stress. Plant Soil 192:307-319.

De Kreij, C., W. Voogt, A.L. van den Bos, and R. Baas. 1997. Voedingsoplossingen voor de teelt van tomaat in gesloten teeltsystemen. Proefstation voor Bloemisterij en Glasgroente. Naaldwijk, The Netherlands, Brochure VG 2, p. 45.
Esmailiyeh, K. P. 1986. $\mathrm{CO}_{2}$ effect on gas exchange and growth of tomato at different salinity (in German). MS thesis, Technische Universität Berlin.

Gao, S., W.L. Pan, and R.T. Koening. 1994. Integrated root system age in relation to plant nutrient uptake activity. Agron. J. 90:505-510.

Göhler, F. 1960. Nutrient use and efficiency during hydroponic cultivation of cucumber and tomato in greenhouses (in German). Arch. Gartenbau 8:146-160.

Göhler, F. and M. Drews. 1989. Hydroponic cultivation systems to produce vegetables in greenhouses (in German). Agrabuch p 108.

Gomez, I., J. Navarro-Pedreno, and J. Mataix. 1992. The influence of saline irrigation on organic waste fertilisation on the mineral content (N, P, K, Na, Ca, and Mg) of tomatoes. J. Sci. Food Agr. 59:483-487. Helgren, O. and T. Ingestad. 1996. A comparison between methods used to control nutrient supply. J. Expt. Bot. 47, 117-122.

Heuer, B. and A. Feigin. 1993. Interactive effects of chloride and nitrate on photosynthesis and related growth parameters in tomatoes. Photosynthetica 28:549-554.

Hoagland, D.R. 1929. The absorption of ions by plants. Soil Sci. 16:225246.

Knight, S.L., R.B. Rogers, M.A.L. Smith, and L.A. Spomer. 1992. Effects of $\mathrm{NaCl}$ Salinity on miniature dwarf tomato 'Micro-Tom': I. Growth analyses and nutrient composition. J. Plant Nutr. 15:2315-2327.

Longuenesse, J.J. and C. Leonardi. 1994. Some ecophysiological indicators of salt stress in greenhouse tomato plants. Acta Hort. 366:461-467.

Maas, E.V. and G.J. Hoffman. 1977. Crop salt tolerance-Current assessment. Journal of the Irrigation and Drainage Division, Proc. Amer. Soc. Civil Eng. 103, IR2, 115-134.

Schwarz, D. and H.-P. Kläring. 2001. Allometry to estimate leaf area of tomato. J. Plant Nutr. 24, 8, 1291-1309.

Schwarz, D. and R. Kuchenbuch. 1997. Growth analysis of tomato in closed recirculating systems in relation to EC-value of the nutrient solution concentration. Acta Hort. 450:169-176.

Smith, M.A.L., L.A. Spomer, R.A. Shibli, and S.L. Knight. 1992. Effects of $\mathrm{NaCl}$ salinity on miniature dwarf tomato 'Micro-Tom': II. Shoot and root growth responses, fruit production, and osmotic adjustment. J. Plant Nutr. 15:2329-2341.

Sonneveld, C. 1988. The salt tolerance of greenhouse crops. Netherlands J. Agr. Sci. 36:63-73.

Taleisnik, E.L. 1987. Salinity effects on growth and carbon balance in Lycopersicon esculentum and L. penellii. Physiol. Plant. 71:213-218. van den Sanden, P.A.C.M. and B.W. Veen. 1992. Effect of air humidity and nutrient solution concentration on growth, water potential and stomatal conductance of cucumber seedlings. Scientia Hort. 50:173186.

van Iersel, M.W. and B. Bugbee. 2000. A multi-chamber, semi-continuous-crop carbon dioxide exchange system: Design, calibration, and data interpretation. J. Amer. Soc. Hort. Sci. 125:86-92.

Xu, H.L., L. Gauthier, and A. Gosselin. 1995. Effects of fertigation management on growth and photosynthesis of tomato plants grown in peat, rockwool and NFT. Scientia Hort. 63:11-20.

Xu, H.L., J. Lopez, F. Rachidi, N. Tremblay, L. Gauthier, Y. Desjardins, and A. Gosselin. 1996. Effect of sulfate on photosynthesis in greenhouse-grown tomato plants. Physiol. Plant. 96:722-726. 